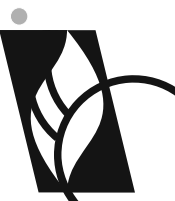

J O U R N A L

$\mathrm{O} F \bullet \mathrm{B} \mathrm{A} \mathrm{L} \mathrm{T} \mathrm{I} \mathrm{C}$

$S$ C I E N C E

E DUCATION

\section{ISSN 1648-3898 /Print/ ISSN 2538-7138}

\title{
CHEMISTRY TEACHERS' ASSESSMENT LITERACY IN TURKEY
}

Abstract. The aim of this research was to find out the assessment literacy level of chemistry teachers in Turkey. For the purpose of the research, different types of formative assessment techniques were included in the research. This research was conducted as a case study, which is a kind of qualitative research design. The participants in the research were 12 chemistry teachers working in different high schools in Şanlıurfa, one of the largest cities in south-eastern Turkey in 2017-2018 spring term. Research data were collected with a semi-structured interview form.

Content analysis was performed on the research data. According to the results, chemistry teachers did not have sufficient perception and knowledge about diagnostic and formative assessment. Chemistry teachers' perception related to objective of formative assessment techniques was very low and it was almost unfamiliar to them. Also, chemistry teachers had little percep-

tion about how formative assessment techniques should be prepared and what is their function. Their perception related to the interpretation/scoring of the results obtained from formative assessment techniques was almost non-existent. They had serious deficiencies related to formative assessment techniques and they focused on summative assessment rather than formative assessment and related techniques in their chemistry classes.

Keywords: assessment literacy (AL), chemistry teachers (CTs), formative assessment techniques (FATs), Turkey.

Mehmet Diyaddin Yaşar Harran University, Turkey

\section{Mehmet Diyaddin Yaşar}

\section{Introduction}

The changing demands of the individual and society, developments in science and technology, approaches of learning and teaching, paradigms and theories, and the results of the national and international research are bringing together the need to update, improve, and modify the curricula (Ministry of National Education; MoNE, 2017.) These changes and developments find their reflection in Science and Chemistry curriculum, too. In science classes, pupils are expected to achieve meaningful learning (Abell \& Siegel, 2011). With the change of paradigms for learning, several changes are observed in educational reforms and curricula in many countries around the world. In line with global developments, changes are also being introduced to science curricula in Turkey; as a result, the curriculum was rearranged in 2017 (MoNE, 2017). The changes in the curriculum require teachers to obtain necessary knowledge, skills, and competences. Thus, teachers are encouraged to participate in research studies and deal with research evidences related to their own classes and use the results of scientific research for increasing the success of their pupils (Cooper \& Cowie, 2010). Besides, there is a widespread belief that teachers should utilize assessment to develop and help pupils' learning and achievement (Black \& Wiliam, 1998; Cooper \& Cowie, 2010; Popham, 2006).

Science education is improving overall knowledge related to effective organization and use of assessment in science classes. However, only few research can be seen to examine teachers'knowledge, perception, and implementation related to assessing science learning (Lyon, 2013). Besides, most of the teachers do not feel well-prepared for assessment, and they need support to apply and make decisions based upon various types of assessment techniques (Mertler \& Campbell, 2005). Therefore, it is vital for improvement and progression of science education that science teachers and candidates use effective assessment approaches and activities (Lyon, 2013). Teacher education programs also perform a great endeavour to support prospective teachers gain the information and abilities needed to succeed in their forthcoming professions (Yılmaz-Tüzün, 2008). Prospective teachers need to graduate from these programs after they obtain in-depth professional knowledge and necessary skills. If they acquire satisfactory information related to assessment through the teacher education programs graduated, they are likely to be confident and capable of applying various kinds of assessment techniques (Yılmaz-Tüzün, 2008).

One of the goals of assessment in education is to report and develop the 
continuous learning of pupils and the teaching of curricula (Cowie \& Bell, 1999). Classroom assessment for learning is a remarkable and cost-effective way of improving and enhancing pupils' learning (Popham, 2006). Assessment made to improve learning and teaching is called formative assessment (Cowie \& Bell, 1999). Traditional approach to assessment in which teachers perform testing mainly to determine what those pupils know, is defined as assessment of learning. On the other hand, instructionally oriented approach in which assessing plays an important role to help pupils learn, is called assessment for learning (Popham, 2006). When the related literature is examined, it is seen that different terms such as assessment expertise (Lyon, 2013), assessment identity (Looney, Cumming, Kleij, \& Harris, 2017), assessment literacy (Abell \& Siegel, 2011; Xu \& Brown, 2016) are employed to explore comprehensions, qualifications, and applications of the teachers related to classroom assessment. Assessment expertise refers to teachers' beliefs and knowledge about assessment named as assessment understanding and how teachers use these beliefs and knowledge in planning assessment, assessing learning-teaching, and reflecting on assessment practices defined as assessment facility (Lyon, 2013). Teachers' belief in assessment, their tendency and competence, and their perceptions of their role as an evaluator are important in the assessment process and defined as the assessment identity (Looney, Cumming, Kleij, \& Harris, 2017). Assessment literacy includes how assessment is organized and applied, how assessment data are employed and interpreted by the teachers and it becomes an important part of teacher professionalism and education (Abell \& Siegel, 2011). Assessment literacy is described as the information and abilities that teachers need to improve and practice for the purpose of exploring what pupils know and are able to do, what to assess with assessment strategies and interpreting the results of the assessment to decide how to remedy and develop pupils'learning and efficiency of the curriculum (Abell \& Siegel, 2011; Looney, at. al., 2017; Xu \& Brown, 2016). Abell and Siegel (2011) have developed a model of assessment literacy, which includes teachers' views of learning and worth of assessment and knowledge of the purpose of assessment, what to assess, assessment strategies, and interpretation of assessment results.

Referring to research on science education in Turkey, only $3 \%$ of these studies deal with assessment and evaluation, which are heavily comprised of tests, scale development and adaptation studies (Sözbilir, Kutu \& Yaşar, 2012). It applies to chemistry education, too. Sözbilir, Akıllı, Yaşar and Kutu (2016) note that only $6.8 \%$ of chemistry education covers assessment and related studies in national and international research. Moreover, these are mostly about tests, scale development or adaptation studies. There have been conducted few studies about assessment and related studies in science education (Şenel-Çoruhlu, Er-Nas, \& Çepni, 2009; Sağlam-Arslan, Devecioğlu-Kaymakçı, \& Arslan, 2009), in chemistry education (Şenel, Pekdağ, \& Günaydın, 2018), and in mixed studies such as physics, chemistry, biology, and mathematics education (Bayat \& Şentürk, 2015; Nazlıçiçek \&Akarsu, 2008). All these works on assessment are about perception, but the implementation of curricula by science teachers is explored rather superficially in Turkey. In above mentioned research, it has been reported that science teachers implement the curricula without having adequate information and abilities about formative assessment techniques and this causes some problems in practice (Şenel-Çoruhlu, Er-Nas, \& Çepni, 2009; Sağlam-Arslan, Devecioğlu-Kaymakçı, Arslan, 2009). In addition, chemistry teachers have been found to feel inadequate about using formative assessment techniques as stated by Şenel, Pekdağ and Günaydın (2018). Bayat and Şentürk (2015) have explored physics, chemistry and biology teachers' opinions about formative assessment approaches to note that teachers have insufficient knowledge and skills in the preparation and implementation of these approaches. Also, Nazlıçiçek, and Akarsu (2018) have carried out examination on mathematics, physics and chemistry teachers' knowledge and implementation related to assessment techniques. They have reported that teachers have a lower level of information regarding portfolios, concept maps, daily and experiment report techniques than the others, which leads to inability to achieve the desired efficiency at practical stage. As understood from the limited number of particular research conducted with science and chemistry teachers, there have been few examples probing into teachers' knowledge and skills about formative assessment techniques. In addition, it is seen that there are not enough field studies on chemistry teachers' proficiency and perception related to the aim of assessment, definition and preparation of assessment strategies, what to assess and how to interpret/ score results and data obtained from formative assessment techniques and how to put these strategies into practice in their chemistry classes in Turkey. The present research targets to close such research gap. Besides, as an examination in detail, it is hoped to do a considerable contribution to the particular piece of literature about dimensions of assessment lacked by chemistry teachers. In this context, the results of this research provide important feedback to teachers, teacher candidates, educators, academicians, experts, administrators and decision makers at their respective work.

The changing perspective on learning leads to the shaping of assessment and evaluation, which is an important part of the curriculum. Assessment acts a vital role in secondary and senior high school science classrooms, both in reporting what pupils know, which influences their progression along with the curriculum and in supporting pupils' 
learning of science (Lyon, 2013). It is seen that both assessment of learning and assessment for learning have come to the fore together in chemistry curricula in Turkey. In Turkish chemistry curriculum, it is seen that not only product but also process assessment are at the forefront, and the assessment approach that supports pupils' learning is dominant (MoNE, 2017; MoNE, 2018). Parallel to the increasing interest in formative assessment from 1980s to present, less attention is being paid to both teachers' perception and quality implementation (Wylie \& Lyon, 2015). According to Box, Skoog, and Dabbs (2015), teachers are the core of the learning-teaching environment as they do curricular judgements that influence what, how and if or not pupils learn. Therefore, this research is planned with the intention of unearthing chemistry teachers' perceptions and applications about formative assessment and related techniques to reveal the complexity of implementation of these techniques in chemistry classrooms. In order to bridge the gap between theory and practice, obstacles that hinder qualified practices should be identified. The present research aimed to scrutinise chemistry teachers' assessment literacy. Thus, it attempted to shed light onto how the formative assessment techniques such as performance assessment (PA), portfolio (P), diagnostic branched tree (DBT), structured $\operatorname{grid}(\mathrm{SG})$, word association test (WAT), concept map (CM), interview (I), observation (O), self-assessment (SA), and peer assessment $(\mathrm{PeA})$ are perceived by chemistry teachers and how they reflect these techniques into practice in their chemistry classes. Here answer was sought for the following questions.

1. What was the CTs' perception level related to purpose of assessment?

2. What was the CTs' perception level related to objective of formative assessment techniques?

3. What was the CTs' perception level related to formative assessment strategies/techniques?

4. What was the CTs' perception level related to interpreting/scoring the results obtained in the formative assessment techniques?

5. What was the CTs' implementation level related to formative assessment techniques in their classes?

\section{Research Methodology}

\section{Research Design}

As Box, Skoog, and Dabbs (2015) have pointed out, there are many quantitative research about formative assessment but it requires the use of a qualitative approach because of the complexity, multi-layered and dynamic of teachers'judgements concerning formative assessments. This research was conducted as a case study which is a kind of qualitative research design (Bogdan \& Biklen, 2007) or a qualitative research strategy (McMillan \& Schumacher, 2010). The case study is a detailed description and investigation of a limited and specific situation, a system and a single entity (Meriam, 1998; McMillan \& Schumacher, 2010). In the current research, detailed descriptions and examinations were made about the perceptions and practices of chemistry teachers related to formative assessments with interviews.

\section{Participants}

The participants in the research were 12 chemistry teachers working in different senior high schools in Şanlıurfa, one of the largest cities in south-eastern Turkey during the 2017-2018 spring term. Approval of and agreement for this research was provided by Provincial Directorate of National Education Management which chemistry teachers were engaged including senior high schools. The teacher took part in the research after the necessary permissions were granted by Şanlıurfa Provincial Directorate of National Education Management. Senior high school managers, administrative staff and chemistry teachers were made familiar with the research and procedures within it. All the teachers were asked if they wanted to participate herein and they agreed to do so. All chemistry teachers were included on a voluntary basis. The anonymity of all chemistry teachers and confidentiality were guaranteed. All participants were reminded of the guarantees regarding confidentiality and anonymity at every stage of the research process, and were taken permission to record interviews and use the interview data. The selection of the participants was concluded through convenience sampling among non-probability sampling methods (McMillan \& Schumacher, 2010). In this sampling method, the main intent is to ensure a better comprehension of the existing situations or relations than generalization (McMillan \& Schumacher, 2010) and it is essential to choose participants that are close, easy to access and volunteer to take part in the research (Büyüköztürk, Kılıç-Çakmak, Akgün, Karadeniz \& Demirel, 2008). The similarities and differences of the research sample regarding age, gender, experience of teaching chemistry, the educational level and administrative duty are listed in Table 1. 
Table 1

The demographic findings of CTS

\begin{tabular}{|c|c|c|c|c|}
\hline \multicolumn{5}{|l|}{ Age } \\
\hline $20-25$ & $26-30$ & $31-35$ & $36-40$ & 41 and over \\
\hline- & T 8 & T6 & $\mathrm{T} 1,7,9$ & T 2, 3, 4, 5, 10, 11, 12 \\
\hline \multicolumn{5}{|l|}{ Gender } \\
\hline Female & \multirow{2}{*}{\multicolumn{3}{|c|}{$\begin{array}{l}\text { Male } \\
\text { T } 1,2,5,6,7,10,11,12\end{array}$}} & \\
\hline T $3,4,8,9$ & & & & \\
\hline \multicolumn{5}{|c|}{ Teaching Chemistry Experiences } \\
\hline $1-5$ & \multirow{2}{*}{$\begin{array}{l}6-10 \\
-\end{array}$} & \multirow{2}{*}{$\begin{array}{l}11-15 \\
\mathrm{~T} 6,11\end{array}$} & $16-20$ & \multirow{2}{*}{$\begin{array}{l}21 \text { and over } \\
\mathrm{T} 3,4\end{array}$} \\
\hline $\mathrm{T} 7,8$ & & & $\mathrm{~T} 1,2,5,9,10,12$ & \\
\hline \multicolumn{5}{|l|}{ Educational Level } \\
\hline & \multirow{2}{*}{\multicolumn{3}{|c|}{$\begin{array}{l}\text { MSc } \\
\text { T } 7,9\end{array}$}} & $\mathrm{PhD}$ \\
\hline T 1, 2, 3, 4, 5, 6, 8, 10, 11, 12 & & & & - \\
\hline \multicolumn{5}{|l|}{ Administrative Duties } \\
\hline $\begin{array}{l}\text { School Principal } \\
\text { - }\end{array}$ & $\begin{array}{l}\text { Deputy School Principal } \\
\text { - }\end{array}$ & \multicolumn{2}{|c|}{$\begin{array}{l}\text { No } \\
\text { T } 1,2,3,4,5,6,7,8,9,10,11,12\end{array}$} & \\
\hline \multicolumn{5}{|l|}{ Type of Senior High School } \\
\hline $\begin{array}{l}\text { Anatolian senior high school } \\
\text { T } 3,4,10,12\end{array}$ & \multicolumn{2}{|c|}{$\begin{array}{l}\text { Science senior high school } \\
\mathrm{T} 1,2,5,6,11\end{array}$} & \multicolumn{2}{|c|}{$\begin{array}{l}\text { Vocational senior high school } \\
\mathrm{T} 7,8,9\end{array}$} \\
\hline
\end{tabular}

T: Teacher. T1, 2... : First teacher, second teacher etc...

\section{Data Collection Tools, Development and Implementation Process}

In qualitative studies, interviews are regarded as the basic data collection strategy (Meriam, 1998). Thus, data were gathered using the semi-structured interview form developed by the author. In such data collection tools, the topic is selected in advance and the researcher decides on the order and expression of the questions during the interview (McMillan \& Schumacher, 2010). Moreover, in semi-structured interviews, the questions offer flexibility and a large part of the interview revolves around the questions and sub-questions (probes) that are needed to be clarified (Merriam, 1998).

The interview form was prepared in three stages. It is based on the author's previous research (Yaşar, 2017): In the first stage, the literature related to formative assessment and affiliated techniques as well as connections that chemistry curriculum has with formative assessments were examined, and decision was made on the type of questions that should be posed to the teachers. In the second stage, two chemistry education experts were invited to review and evaluate the draft interview form both in relation to both content and form. In the third stage, pilot interviews were run with two teacher candidates by performing the semi-structured interview form. As a result of the literature review, field expert opinions and pilot applications; refining works were made in the interview form. Then, the last pattern of the semi-structured interview was constructed and applied in the qualitative research process. With the semi-interview form, 12 chemistry teachers were interviewed at their convenience in teachers' rooms, chemistry classes, laboratories or teachers' offices. Twelve questions were directed to the teachers. Three examples of interview questions and sub-questions (probes) are presented below:

As you know, a number of changes have been made in the chemistry curriculum in 2018 . One element of the chemistry curriculum is measurement-assessment. Do you know specific changes made in the chemistry curriculum? Could you please tell me?

1. What kind of measurement-assessment is foreseen in chemistry courses?

- For what purpose should measurement-assessment be done in chemistry courses?

- What do you understand from the process and the formative assessment?

- What do you understand from the diagnostic assessment?

- What do you understand from the summative assessment? 
2. For what purpose(s) do you do measurement and assessment in your chemistry classes? Could you please explain what you are doing, and give examples of what you do in your chemistry classes?

- To conduct a diagnostic assessment by guiding the determination of the readiness and levels of pupils at the beginning of the course or lesson?

- To conduct formative assessment to monitor the progress of pupils in the learning-teaching process and evaluate the learning-teaching process?

- To do the summative assessment and product assessment to determine pupils' achievements at the end of the semester or year?

- Which kind of measurement-assessment approaches do you prefer (performance assessment, right-wrong, gap filling, open-ended questions, multiple choice, comparative questions, etc.)?

3. What do you think/understand about performance assessment? Why is performance assessment important?

- What is performance assessment?

- What is the purpose of performance assessment and which skills/behaviours/characteristic of the pupils should be assessed?

- How is the performance assessment process carried out / designed / prepared?

- How are scoring / evaluation / interpretation of results conducted in performance assessment?

- Do you use performance assessment in your chemistry classes? Why? /Why not?

- Could you please explain what you are doing by giving examples of what you do in your chemistry classes?

\section{Data Analysis}

Content analysis, which is a type of qualitative data analysis, was applied to the data collected from the interviews. The fundamental process of content analysis is to organize and interpret similar data in a way that the reader can understand by combining within the framework of certain concepts, themes, categories and codes (Yıldırım \& Şimşek, 2008). In content analysis, the existence of certain words or concepts within a set of text or texts is determined and these entities, meanings and relationships are analysed and inferences are made on the message in the text (Büyüköztürk, et. al. 2008).

The data collected here were analysed twice by the author. In the first analysis, the data gathered from the interview procedure was transcribed. The transcripts were read and fully examined and patterns were identified. Assessment literacy is grouped under 5 main categories. During the preparation of these categories, the works of Yaşar (2017) and Apell and Siegel (2011) were taken into consideration. At the end of the content analysis of interviews, 5 essential categories were formed as the "Purpose of Assessment (P of A), Objectives of Formative Assessment Techniques (O of FATs), Definition of Formative Assessment Techniques (D of FATs), Preparation of Formative Assessment Techniques (Pre of FATs) and Interpreting/Scoring of Results of the Formative Assessment Techniques (I/S of FATs) which were produced to elicit the knowledge of chemistry teachers related to formative assessments. The purpose of assessment was divided into 3 codes as Diagnostic Assessment (DA), Formative Assessment (FA) and Summative Assessment (SA) (see Table 2 and Table 3).

During the content analysis, rubrics for the purpose of assessment and each dimension of formative assessment techniques were prepared according to the literature to identify the knowledge and implementation levels of chemistry teachers in relation to the formative assessment techniques defined. The previously determined categories and codes were considered in the preparation process of the rubrics, which were used to realize whether the CTs' perception and implementations could meet the principles of the purpose of assessment and formative assessment techniques highlighted in the related literature. Therefore, the content analysis data were compared to the rubrics created here.

As a result, perception of chemistry teachers about assessment literacy was explained with three codes Strong Perception (SP), Weak Perception (WP) and No Perception (NP) and presented in graphics (see Table 1 and figure through 1 to 9). And the implementation level of chemistry teachers related to purpose of assessment and formative assessment techniques were again compared against three codes Strong Implementation (SI), Weak Implementation (WI) and No Implementation (NI). The results are displayed in graphics (see Table 2 and Figure 10). If the chemistry teacher's knowledge/perception does not contain any misunderstandings, it is classified as strong perception. Respondents with some missing knowledge and misunderstandings are labelled as weak perception. 
Lastly, if the teacher does not reveal any understanding at all, the label no perception is appointed. This was followed in the same way for practices of chemistry teachers according to their views: if the implementation of the teacher does not contain any missing applications, it is labelled as strong implementation. Practical level with some missing applications in some stages is labelled as weak implementation. Lastly, if the practical work does not contain any practices related to stages of formative assessment techniques, it is classified as no implementation.

Three examples of CTs' perception of the objectives of diagnostic branched tree are presented below for each label:

Strong Perception (SP):"(Diagnostic branched tree) allows pupils to notice the missing information (knowledge). When the pupil does not have sufficient knowledge, he/she can reach the wrong information (misconceptions). They (pupils) may have conceptual misconceptions and confusions to concepts. It (diagnostic branched tree) is used both to determine pupil's (conceptual) deficiency and to determine her/his learning" (T7).

Weak Perception (WP): "May be information (knowledge). We can even measure their enjoyments. It depends on the questions that we ask. But the answer is just right or wrong, I think it is a bit superficial (T9).

No Perception (NP): "Okay. I have no idea. We cannot use it, I can't do anything other than that" (T3). "Rather than solving the test-style questions, it offers a slightly wider range than the ready-made ones. It is chosen from there. That's what I understand" (T5).

Three examples of CTs' implementation of observation technique for each label are as below:

Strong Implementation (SI): "Observation method is the marks of conduct on pupils' behaviours that we give throughout the semester. While performing education in the classroom, we observe and evaluate the participation and behaviour reactions of the student in class, etc. Observation method is already oriented towards the (learning) process, not the outcomes. It is an ongoing assessment method throughout the process. And of course there are observation forms... The teacher should be more objective, not behave subjectively, in the preparation (and implementation) of forms... By taking notes or writing in bullet points I mean. Has such behaviour been performed? Yes or no or by partially rating (Observation can be made by)... So, as we said a little before, let's say good, very good or weak or grading 1, 2, 3... (We can score or interpret the results of observation by rubrics). We can ask our questions in this way (to pupils) by grading them as 1, 2, 3, meeting them face to face... We use it in class. The assessment we make in the classroom... we count it in the pupil's behaviour mark." (T7)

Weak Implementation (WI): "It's like we are now... In other words, we can now read their eyes even when we take the pupils to the class at first. So we can understand the body language (of pupils) who can think numerically who can answer the question clearly. (It is an) experience, for example, are we like the first years (of teaching and learning)? No. I know that he/she looks but doesn't listen. It depends on the communication you establish with that pupil with your personal skill. I'm trying not to teach the lesson boring or tight. At least, I'm trying to keep my students awake. I do observations, of course. Once we get to the class with the list. I do student grading in the course with book control, notes from the quizzes etc. I' $m$ taking all these notes apart and I keep notes as + or -. For example, the ones in the series 4, 14, 24... randomly look at the list in one hand... I don't touch those whom I gave priority and follow their progress... I'm not doing anything else. I evaluate (observe) the pros and cons (of pupils)" (T3).

No Implementation (NI): "Actually, I don't use it (observation)" (T2). "Unfortunately we didn't use it (observation) because we couldn't use the lab" (T8).

The data analysis was finished by computing the frequency and percentages of the codes and categories. The collected data were examined and analysed by the author a second time for reliability. The second analysis was fulfilled nearly 3 months after the first run. There should be high reliability between the initial coding and recoding. For this purpose, reliability was computed by using the formula of (Reliability= (number of agreements / total number of agreements + disagreements) and it is recommended that the value closer to $80 \%$ is the best for the reliability by Miles and Huberman (1994, p.64). In this research, reliability was found to be $84.38 \%$ which means a reliable analysis. The findings of the content analysis are displayed in tables (1 and 2) and figures here (from 1 to 10).

\section{Research Results}

This research explored CTs' assessment literacy, especially in formative assessment, through their understanding of assessment and assessment implementation. The findings are presented one by one for each of the research questions. The target of the first four research questions is to elicit chemistry teachers' assessment understanding while the last one related to their assessment implementation. 


\section{Chemistry Teachers' Perception and Understanding of Assessment}

Chemistry Teachers' Understanding/Knowledge of Purpose of Assessment

Teachers' knowledge of purpose of assessment is the first component of assessment literacy. Table 2 shows the CTs' understanding of the purpose of assessment. CTs' perception about the assessment purpose (diagnostic, formative or summative) is summarized in Table 2.

\section{Table 2}

CTs' perception related to purpose of assessment

\begin{tabular}{|c|c|c|c|}
\hline \multirow[b]{2}{*}{ PofA } & \multicolumn{3}{|c|}{ Ac. } \\
\hline & SP & WP & NP \\
\hline DA & $\begin{array}{c}\text { T. } 8 \\
(\mathfrak{f}=1 ; \% 8.33)\end{array}$ & $\begin{array}{c}\text { T. } 2,3,4,6,7,9,10 \\
(f=7 ; \% 58.33)\end{array}$ & $\begin{array}{l}\text { T. } 1,5,11,12 \\
(\mathrm{f}=4 ; \% 33.34)\end{array}$ \\
\hline FA & $\begin{array}{c}\text { T.8, } 10 \\
(\mathrm{f}=2 ; \% 16.67)\end{array}$ & $\begin{array}{c}\text { T.2, 3, 4, 6, 7, 9, } 12 \\
(\mathrm{f}=7 ; \% 58.33)\end{array}$ & $\begin{array}{l}\text { T. } 1,5,11 \\
(\mathrm{f}=3 ; \% 25)\end{array}$ \\
\hline SA & $\begin{array}{c}\text { T. } 3,4,5,6,7,8,9,10 \\
(f=8 ; \% 66.66)\end{array}$ & $\begin{array}{c}\text { T. } 2,12 \\
(\mathrm{f}=2 ; \% 16.67)\end{array}$ & $\begin{array}{c}\text { T. } 1,11 \\
(\mathrm{f}=2 ; \% 16.67)\end{array}$ \\
\hline fT & 11 & 16 & 9 \\
\hline$\% \top$ & 30.56 & 44.44 & 25.00 \\
\hline
\end{tabular}

Ac.: Acronyms. PofA: Purpose of Assessment. DA: Diagnostic Assessment, FA: Formative Assessment; SA: Summative Assessment. T.1,

2, 3...: First, second, third teachers... etc. SP: Strong Perception. WP: Weak Perception. NP: No Perception.

As seen in Table 2, 30.56\% of the CTs reported strong perception, $44.44 \%$ of them reported weak perception, and $25 \%$ of them were found to have no perception for the purpose of assessment. As displayed in the same table, it was found out that $8.33 \%$ of the CTs hold strong perception, $58.33 \%$ weak perception, and $33.34 \%$ hold no perception for DA, which is the first purpose of assessment. As for FA, which is the second purpose of assessment, the ratio of strong-perception teachers was reported as $16.67 \%$, weak perception as $58.33 \%$, and no perception was $25 \%$. Lastly, in SA, the third purpose of assessment, it was found out that the CTs have $66.66 \%$ strong perception, $16.67 \%$ weak perception and $16.17 \%$ no perception.

\section{Chemistry Teachers' Understanding/Knowledge related to Objective of FATs}

Figure 1 reveals chemistry teachers' knowledge of what to assess, especially in formative assessment, as the second component of assessment literacy. As seen in Figure 1, the participant teachers' views related $57 \%$ no perception while $36 \%$ weak and $7 \%$ strong perception related to objective of FATs.

\section{Figure 1}

CTs' perception related to objective of FATs

$$
\equiv \mathrm{SP} \text { WP } \mathrm{NP}
$$

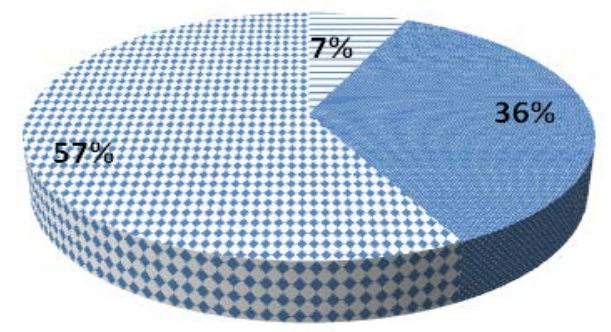


ISSN 1648-3898 /Print/

ISSN 2538-7138/Online/

As seen in Figure 2, it was found out that chemistry teachers hold strong perception related to what to assess with the techniques of SA $(f=3), \operatorname{PeA}(f=2), \mathrm{DBT}(f=2)$ and $\mathrm{O}(f=1)$. Also, the findings of this research showed that CTs have weak perception of what to assess with the techniques such as PA $(f=9), I(f=8), P(f=6)$ and CM $(f=6)$ and SG $(f=1)$; however, they were found to have no idea concerning WAT.

\section{Figure 2}

CTs' perception related to objective of each of the FATs

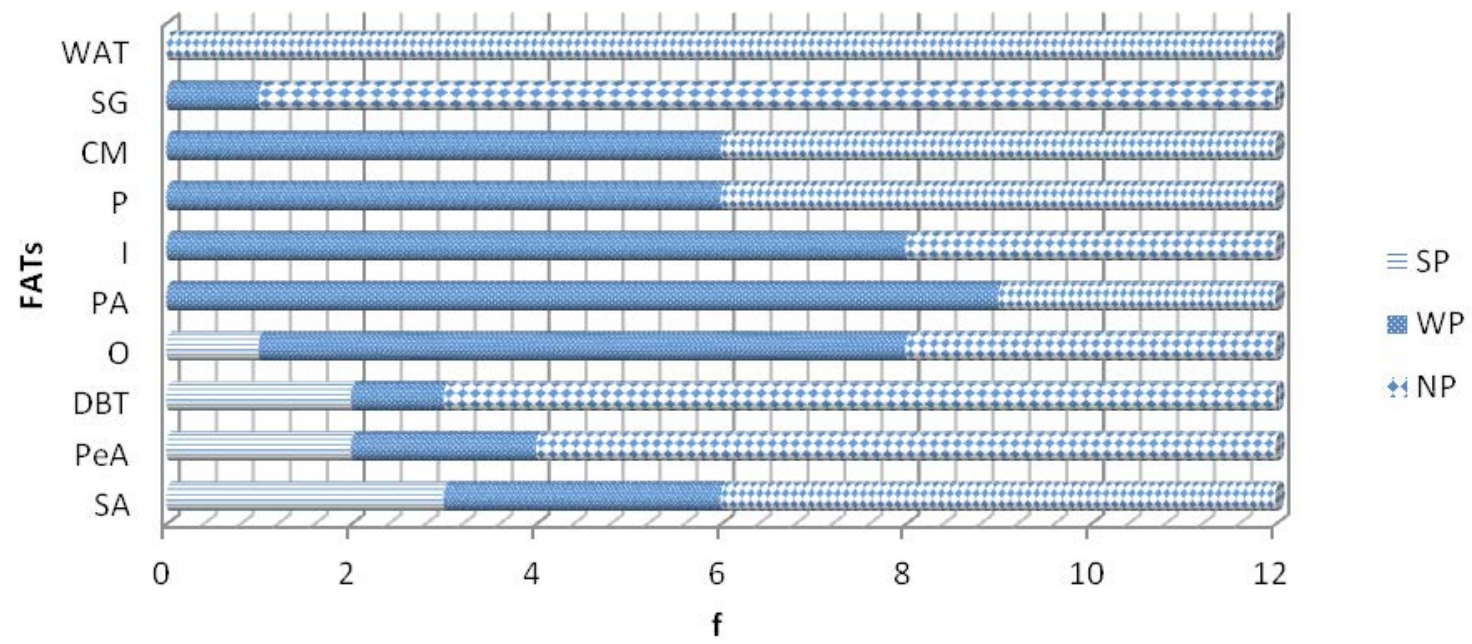

Chemistry Teachers' Understanding/Knowledge of (Formative) Assessment Strategies

Figure 3 shows the perception of CTs on the definition of FATs. As seen in Figure 3, it was understood from the views of CTs that they have $40 \%$ no perception while $33 \%$ weak and $27 \%$ strong perception related to the definition of FATs.

\section{Figure 3}

CTs' perception related to the definition of FATs

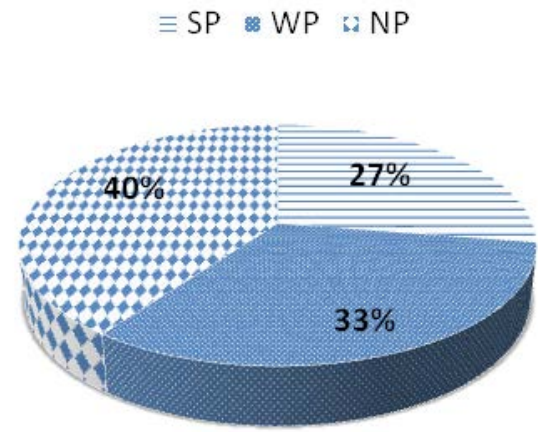

As seen in Figure 4, the results of this research revealed that CTs have strong perception about definition of SA $(f=7)$ and I $(f=6)$ techniques. Figure 4 shows that SG $(f=3)$ and DBT $(f=1)$ are the least defined and recognized techniques by respondents while the WAT is unknown by chemistry teachers as stated in the previous data. From SA to PA, there was a weak tendency towards definition of recognition of formative assessment techniques but it declined gradually. 
CHEMISTRY TEACHERS' ASSESSMENT LITERACY IN TURKEY

(P. 76-9व)
ISSN 1648-3898//Print/

ISSN 2538-7138/Online/

Figure 4

CTs' perception related to definition of each of the FATs

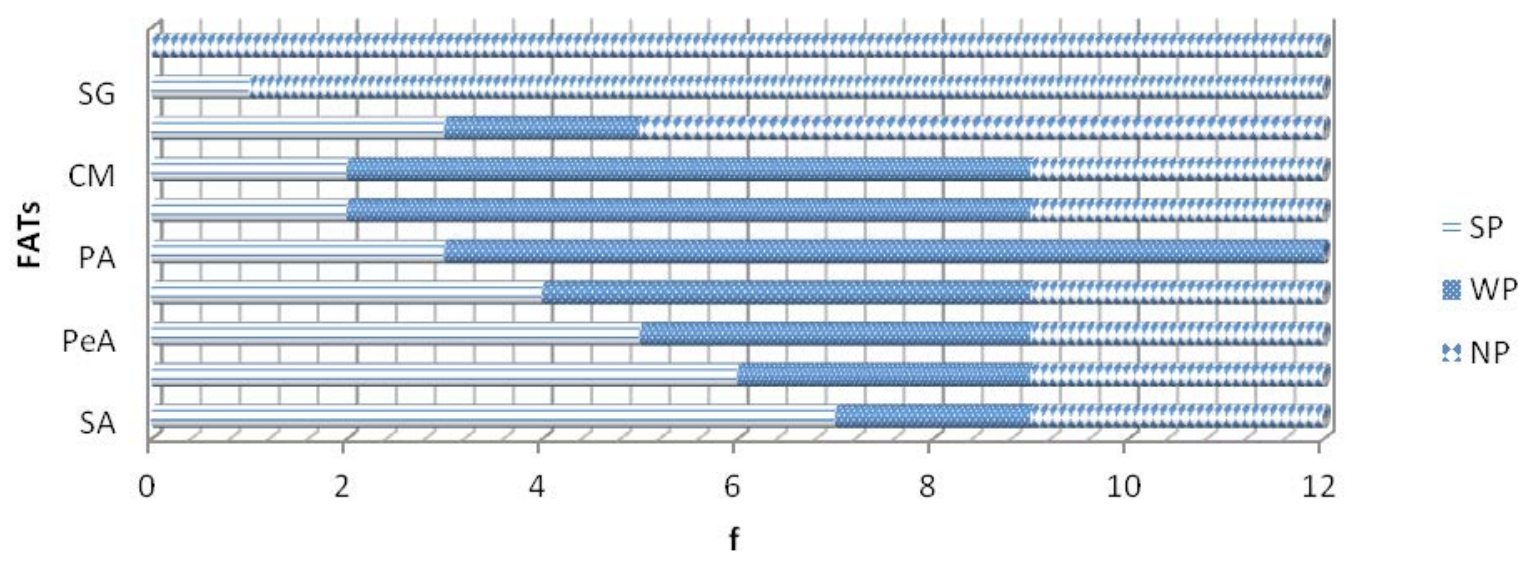

\section{Figure 5}

$C T s^{\prime}$ perception related to the preparation process of FATs

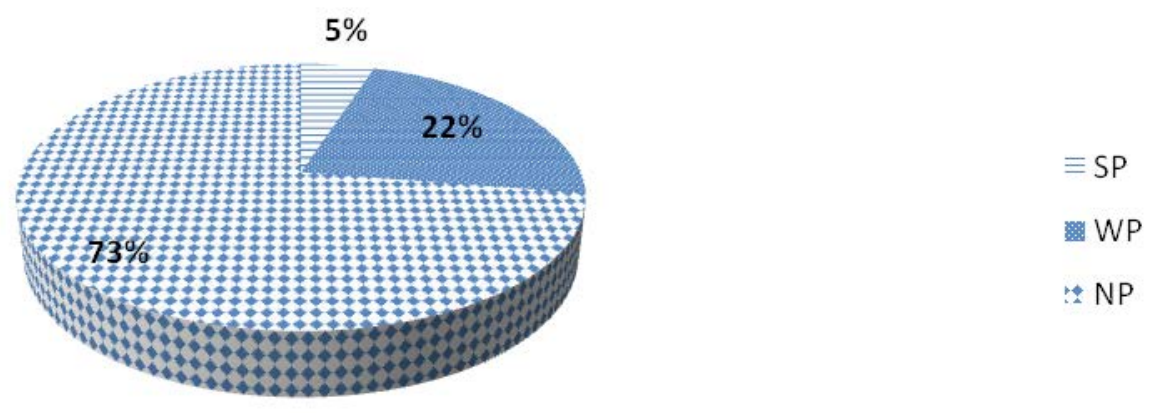

Figure 5 shows the CTs' perceptions about the preparation process of FATs. As seen in Figure 5 , the CTs' views related that $73 \%(f=87)$ have no perception while $22 \%(f=27)$ have weak and $5 \%(f=6)$ have strong perception related to preparation of FATs.

\section{Figure 6}

CTs' perception related to preparation process of each of the FATs

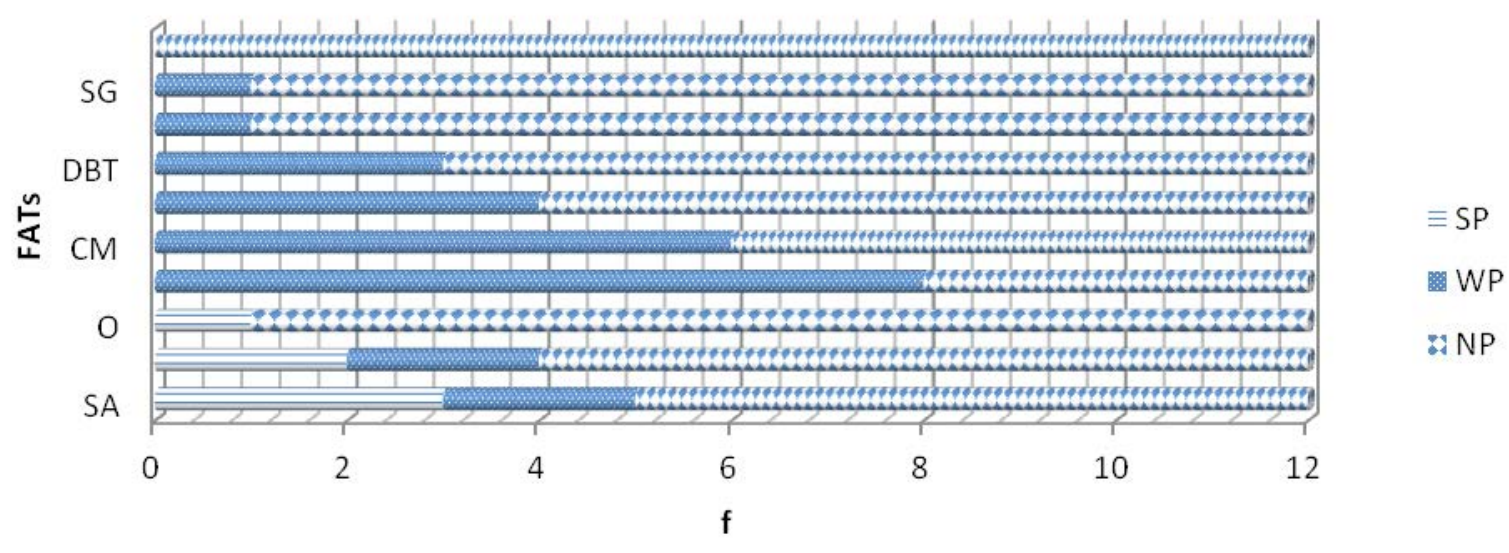


ISSN 1648-3898/Print/

As seen in Figure 6, the results of this research revealed that CTs have strong perception about preparation process of $\mathrm{SA}(f=3), \operatorname{PeA}(f=2)$ and $\mathrm{O}(f=1)$ techniques. Also, the findings of this research displayed that CTs have weak perception about the preparation process of PA $(f=8), C M(f=6), I(f=4)$ and DBT $(f=3)$ techniques. However, the preparation process of $P(f=1)$ and SG $(f=1)$ were the least known and WAT was unknown by them.

\section{Chemistry Teachers' Understanding/Knowledge of Interpretation/Scoring Results of FATs}

Figure 7 illustrates the CTs' perceptions about interpretation and scoring results of FATs. As seen in Figure 7, it was understood from the CTs' views that they have $88 \%$ no perception while $10 \%$ weak and $2 \%$ strong perception about how to interpret results of FATs.

\section{Figure 7}

CTs' perception related to the interpretation/scoring results of FATs

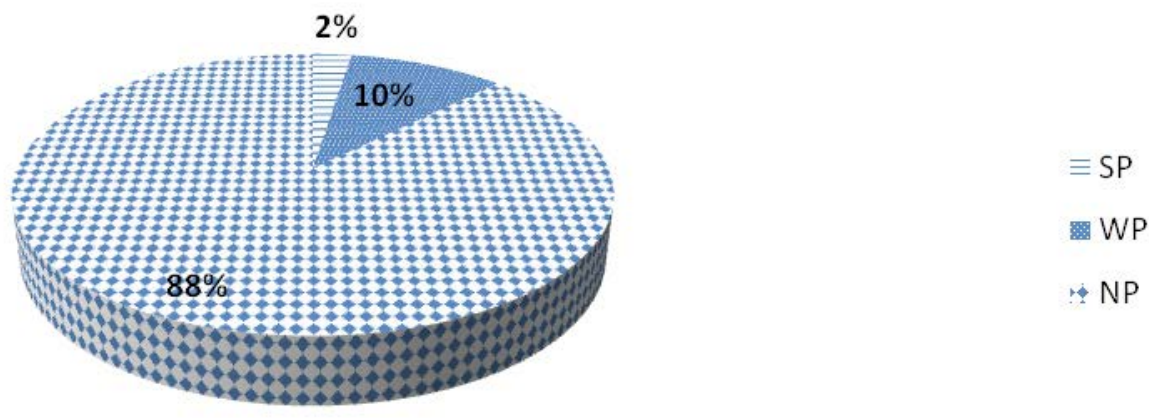

As seen in Figure 8, the results of this research revealed that great amount of CTs have no perception about interpreting results of PA ( $f=7)$, DBT $(f=9), \mathrm{O}(f=11), \mathrm{SA}(f=11), \mathrm{P}(f=11), \mathrm{CM}(f=11), \mathrm{SG}(f=11), \mathrm{I}(f=11), \mathrm{PeA}(f=11)$ and WAT ( $f=12)$ techniques. Only a small number of the $C$ Ts reported strong perception related to interpreting results and data obtained from PA $(f=1), \mathrm{O}(f=1)$ and $\mathrm{SA}(f=1)$ techniques.

\section{Figure 8}

$C T s^{\prime}$ perception related to interpretation/scoring results of each of the FATs

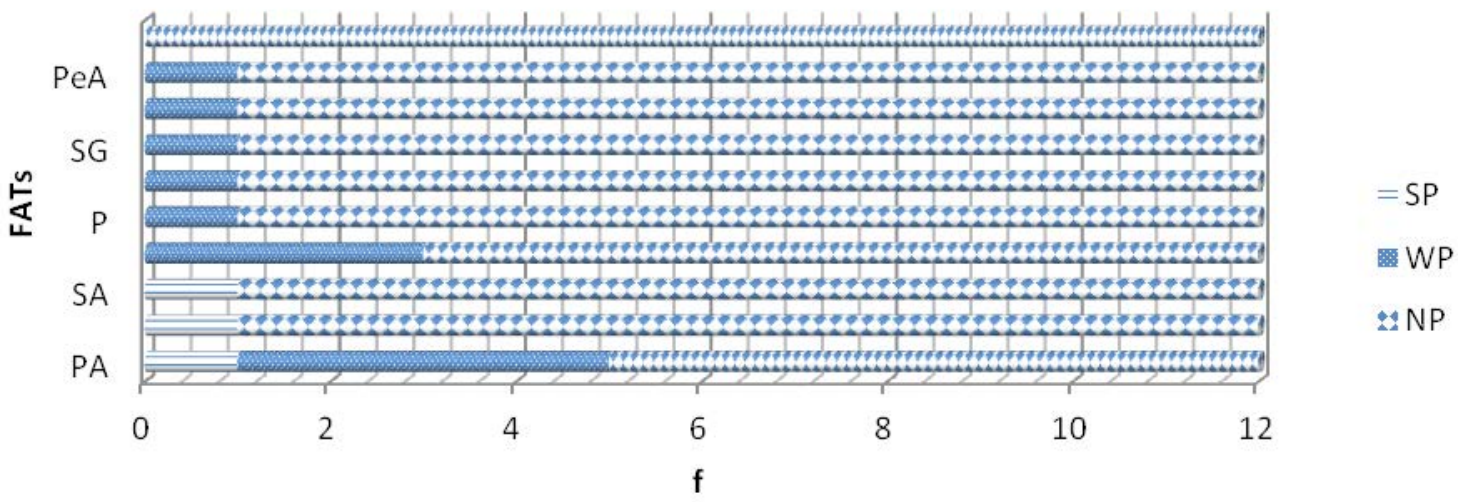

Figure 9 below illustrates the perception/knowledge of CTs related to purpose of assessment, what to assess, assessment strategies, and interpreting/scoring results/data in order to create integrity and a holistic perspective. As the figures display, $30.56 \%$ of the participant teachers could indicate strong perception, $44.44 \%$ weak perception, and $25 \%$ declared no perception related to purpose of assessment, which is the first component of the assessment literacy. Similar to the knowledge of (formative) assessment strategies, $27.5 \%$ of the CTs were found strong perception, $32.5 \%$ weak perception and $40 \%$ no perception or no knowledge. Also, it is seen in Figure 9 that CTs had $6.67 \%$ strong perception, $35.83 \%$ weak perception and $72.5 \%$ no perception related to objective of the FATs. However, $2.5 \%$ had strong, $10 \%$ weak, and $87.5 \%$ had no perception related to the interpretation and 
scoring result of FATs. As seen in Figure 9 below, it was found out that chemistry teachers have a perception and knowledge that decreased from the assessment purpose towards the interpretation and scoring results obtained from formative assessment techniques.

\section{Figure 9}

$C T s^{\prime}$ perception related to components of assessment literacy $(A L)$

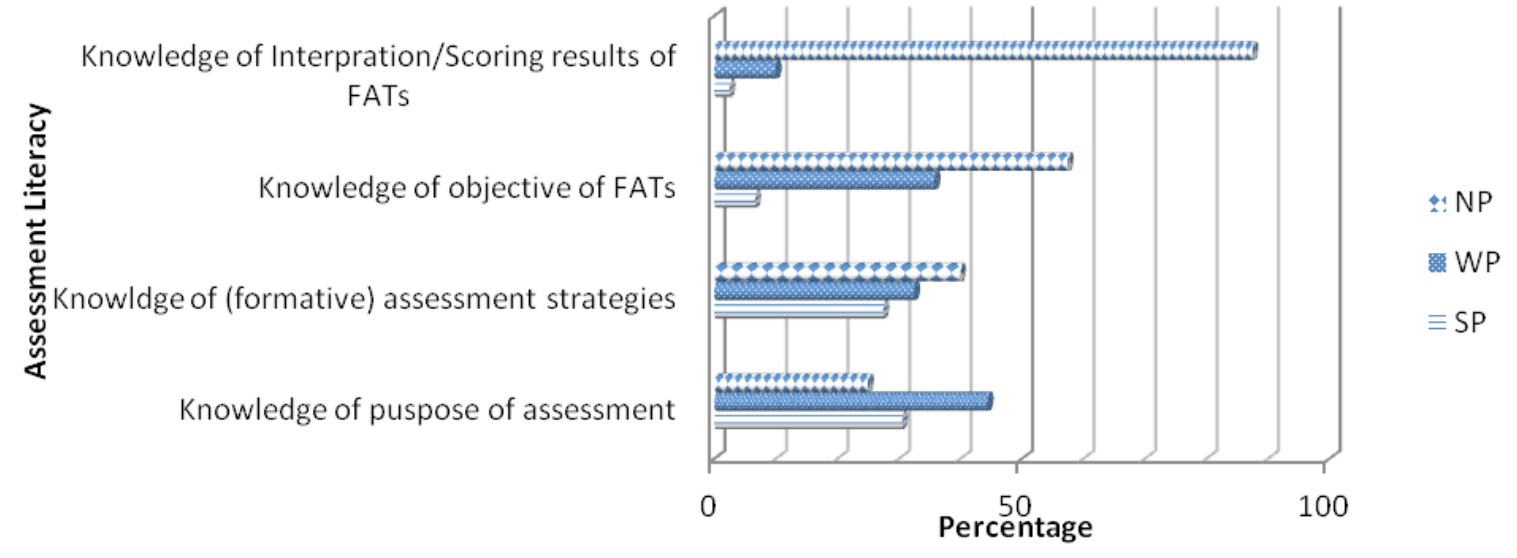

\section{Chemistry Teachers' Assessment Implementation of FATs}

Table 3 indicates the CTs' assessment purpose in the implementation in their classes. Their implementation related to the assessment purpose, which consists of three main objectives as diagnostic, formative and summative, is displayed in Table 3. As Table 3 reveals, $33.33 \%$ of chemistry teachers here could implement the purpose of formative assessment techniques at a strong level and $44.45 \%$ of them at a weak level while $22.22 \%$ of CTs could not implement at all.

\section{Table 3}

CTs' implementation level of purpose of assessment

\begin{tabular}{|c|c|c|c|}
\hline \multirow{2}{*}{ PofA } & \multicolumn{3}{|c|}{ Ac. } \\
\hline & SI & WP & NI \\
\hline DA & $\begin{array}{c}- \\
(\mathrm{f}=0)\end{array}$ & $\begin{array}{c}\text { T.1, 3, 4, 7, 8, } 9 \\
(\mathrm{f}=6 ; \% 50)\end{array}$ & $\begin{array}{c}\text { T.2, } 5,6,10,11,12 \\
(\mathrm{f}=6 ; \% 50)\end{array}$ \\
\hline FD & $\begin{array}{c}- \\
(\mathrm{f}=0)\end{array}$ & $\begin{array}{c}\text { T.1, 2, 3, 4, 6, 7, 8, 9, 10, } 12 \\
(\mathrm{f}=10 ; \% \text { 83.33) }\end{array}$ & $\begin{array}{c}\text { T.5, } 11 \\
(\mathrm{f}=2, \% \text { 16.67) }\end{array}$ \\
\hline SD & $\begin{array}{c}\text { T.1, } 2,3,4,5,6,7,8,9,10,11,12 \\
(\mathrm{f}=12 ; \% \text { 100) }\end{array}$ & $\begin{array}{c}- \\
(\mathrm{f}=0)\end{array}$ & $\begin{array}{c}- \\
(\mathrm{f}=0)\end{array}$ \\
\hline$f$ & 12 & 16 & 8 \\
\hline$\%$ & 33.33 & 44.45 & 22.22 \\
\hline \multicolumn{4}{|c|}{$\begin{array}{l}\text { As seen in Figure } 10 \text {, the CTs declared a high level of implementation related to observation }(f=1) \text { technique. } \\
\text {, as seen in Figure } 10 \text {, some of the chemistry teachers were found to apply weak implementation related to PA } \\
0), I(f=8) \text { and } O(f=7) \text { techniques. A large number of them stated no implementation related to } P(f=11) \text {, DBT } \\
\text { 1), CM ( } f=11) \text {, PeA }(f=11) \text { techniques. However, one of the most striking results displayed that such techniques } \\
\text { A, WAT and SG were not used by chemistry teachers in their classes. }\end{array}$} \\
\hline
\end{tabular}




\section{Figure 10}

CTs' implementation related to each of the FATs

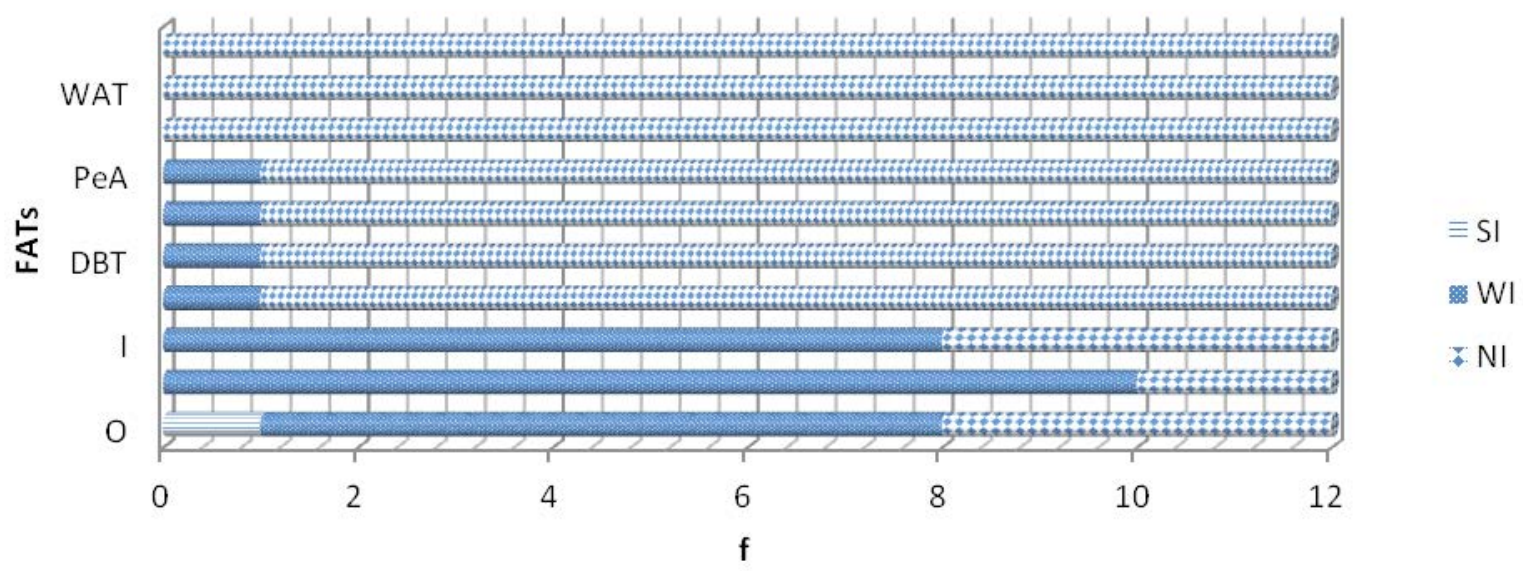

\section{Discussion}

Perception and knowledge of the CTs related to the purpose of assessment was addressed as can be seen in Table 1. The first purpose of assessment is the diagnostic assessment, which happens at the beginning of learningteaching, lesson unit or course (Abell \& Siegel, 2011). According to the present research, it was observed that only one chemistry teacher has strong perception while most of the CTs $(f=7)$ are in the opposite status about diagnostic assessment and a significant number of CTs $(f=4)$ do not even perceive it. The second purpose of assessment is formative assessment, which allows giving feedback to the pupils and ensures identification and elimination of deficiencies during the learning-teaching process (Abell \& Siegel, 2011). The current research revealed that two chemistry teachers perceive formative assessment at strong level as desired, while the majority has a weak perception $(f=7)$, and a significant number $(f=3)$ do not have any perceptions or knowledge about it. The third purpose of assessment is summative assessment, which occurs at the end of the learning-teaching process and allows assessing and grading the learners' achievement and grading (Abell \& Siegel, 2011). According to the results obtained from the research, chemistry teachers seem to be most familiar and informed (at $66.66 \%$ ) about this dimension of assessment.

The perception of CTs about the objectives of FATs is summarized in Figures 1 and 2. It could be inferred that the objective of SA, PeA, DBT and $\mathrm{O}$ is perceived sufficient by only few chemistry teachers, constituting a significantly lower ratio at the same time. Furthermore, the objective of PA, I, P, CM and SG was perceived at a weak or low level by some CTs, but this level was not sufficient and even decreased gradually. Science teachers need to know assessing the behaviours and skills occur at the learning-teaching process (Abell \& Siegel, 2011). This is defined as "what to assess" which is about objectives of curriculum and values what is crucial for learning and how it takes place. However, according to the findings obtained from the research, CTs do not have adequate understanding and perception about what to assess with each of FATs.

Science teachers must know about how to utilize summative and formative strategies in their courses which is called knowledge of assessment strategies (Apell \& Siegel, 2011). In this research, an examination was carried out into CTs' knowledge of assessment strategies related to FATs. This part consisted of two pillars as definition (Fig. 3. and 4) and preparation process (Fig.5 and 6) of FATs. It is believed that a chemistry teacher should have an adequate-understanding and perception of definition and preparation process of FATs for successful implementation of them. The findings revealed that the function of some FATs is recognized and perceived sufficient by few CTs, and this ratio was quite low. SA, I, PeA and $O$ were the best known techniques by chemistry teachers; still, the ratio was found to seem very low. When it came to PA, P, DBT and SG techniques, the ratio gradually decreased. In the end, they were almost unrecognizable and unknown by the CTs. Apart from that, WAT was not recognized and its function was unknown and unused by the CTs. However, the first condition for successful implementation of a FAT is that the technique and its function should be available satisfactorily to the teachers. Although the preparation 
process of $\mathrm{SA}, \mathrm{PeA}$ and $\mathrm{O}$ was perceived adequate by some $\mathrm{CTs}$, this figure was considered quite low. The findings of this research showed that the preparation process of PA, CM, I, DBT, P and SG techniques are also perceived at a weak level by some CTs. However, it was found insufficient and even showed a decreasing tendency.

CTs' perception and understanding of the interpretation and scoring of the result of the FATs are summarized in Figures 7 and 8. The interpretation and scoring of the results obtained from the PA, $\mathrm{O}$ and SA approaches is found sufficient by only few chemistry teachers, the ratio still remaining quite low. Teachers'knowledge and understanding about interpreting assessment results and organizing and adjusting learning-teaching environment considering assessment data is an important part of the assessment literacy (Abell \& Siegel, 2011). The results of the current research represented that the teachers find interpretation, assessment and reflecting on the results most troubling and challenging, as in Izci and Siegel (2019).

In the second part of this research, insight was sought into how CTs incorporate each FAT into practice in their classes. Table 2 shows what teachers aim for and are doing, while Figure 10 shows which FATs they use in their own chemistry classrooms. As regards formative assessment, as seen in Figure 10, it was understood that some of the CTs apply observation technique at a strong level in their classes. The findings revealed that $\mathrm{O}, \mathrm{PA}$ and I techniques are mostly tried to be applied by most of CTs while P, DBT, CM and PeA techniques are applied by a very small number of CTs at a weak level in their classes. However, it was seen that SG, SA and WAT techniques have never been used in chemistry classes. Box, Skoog, and Dabbs (2015) point out that form of teachers of knowledge acts a crucial role in shaping their assessment applications and affect their capability to transform proposed theories related to the assessment into real classroom practices. Supporting this, there was a parallelism between teachers' knowledge/ perceptions and practices of FATs in Turkey. Although such techniques as SA, I, PA and O techniques were best known by CTs, they did not use SA while using O, PA and I techniques strongly or weakly in their classes. However, this did not mean that teachers focus on formative assessment in chemistry courses. These findings were compared with those of Box, Skoog, and Dabbs (2015) Chen and Wei (2015) and Izcl and Siegel (2019) which have announced that chemistry and science teachers in their class or learning-teaching process could not achieve to transfer their thoughts related to learner centred learning and formative assessment into their classroom applications because of pupils' expectations, habits and bias, high-stake public assessment and university entrance examination luck of theoretical and strategic knowledge, experiences, time requirement and also overcrowded classrooms. Similar to Box, Skoog, and Dabbs (2015) and Chen and Wei (2015), these barriers and constraints force teachers to cover the whole of the curriculum to make ready their pupils for the end-of-year exams, high-stake tests and university entrance examination; and to use traditional rather than constructivist and learner centred approaches to teaching and learning. The results of this research were in compliance with the findings of Gelbal and Kelecioğlu (2007), which have explored teachers' competence perceptions related to measurement and assessment techniques and issues they faced and indicated that majority of the teachers prefer traditional assessment approaches and they need training about the use and preparation of the formative assessment techniques. Findings of the present research also seem in parallel with Özgenç and Çakır (2015) who have analysed primary school teachers' competencies and self-efficacy belief of FATs and concluded that teachers need training support for not only understanding of these techniques but also how to put these techniques into practice. Also, this current research revealed similar results in the implementation process of the assessments like Izci and Siegel (2019) who have searched an alternatively new chemistry teacher's assessment literacy and found out that chemistry teacher had adequate understanding but she could not adapt her knowledge of assessment into classroom practice as she desired.

\section{Conclusions}

The purpose of this research was to discuss the assessment literacy of chemistry teachers. For the purpose of the research; PA, P, DBT, SG, WAT, CM, I, O, SA and PeA, which are formative assessment techniques, were considered here. Thus, it was attempted to reveal how each formative assessment technique is perceived in theory and how they are integrated into practice by chemistry teachers. Therefore, the research was comprised of two parts discussing the perception/knowledge level and implementation level of CTs on formative assessment techniques, respectively.

The findings revealed that CTs do not have adequate perception and understanding about diagnostic assessment and formative assessment. This suggested that chemistry teachers have a traditional perception and understanding of assessment. Moreover, nine of chemistry teachers comprised a considerable part of the respondents and they were not aware of the purpose of assessment at all. It could be concluded from the findings that the 
understanding and perception of chemistry teachers related to the objective of FATs is very low and it is almost completely unfamiliar to them. It was seen that teachers do not know which behaviours, skills and gains would be assessed with FATs in chemistry classes. According to the findings, chemistry teachers did not recognize the FATs adequately and they had serious deficiencies about the function of the techniques. The findings also showed that chemistry teachers have little perception about how FATs should be prepared. The findings implied that chemistry teachers' perception and understanding about the interpretation of the results obtained from FATs and its inclusion into the learning-teaching process and giving feedback to the pupils with these techniques, is almost non-existent. Our findings displayed that CTs focus on summative assessment, i.e., assessing student achievement, and they include formative assessment at a weak level in their classes at the same time. Chemistry teachers mostly focused on summative assessment in their classes because of their traditional understanding of assessment.

While this research was conducted as a case study with 12 chemistry teachers and data were collected via interviews, it is believed that long term and in-depth interviews with chemistry teachers of different age, stages of their careers and experiences and from different types of schools could allow drawing conclusions that may have suggestions for chemistry teachers with the inclusion of pre-service, novice, experienced and working teachers. However, it is not intended to generalize the results of this research to other teachers in different fields, cities or countries. It was expected to inform teacher educators, experts and police makers to know the difficulties faced by chemistry teachers and find ways and solutions to support pre-service and in-service teachers both in theoretical knowledge of assessment literacy and transfer it into classroom practices. To sum up, the present research gives insights to them related to the complicacy of how chemistry teachers do assessment-related judgements and grasp the difficulties of implementation of FATs.

\section{Note}

This research was presented at the $5^{\text {th }}$ International Congress on Education Sciences and Learning Technology (ICESLT) Sarajevo, Bosnia and Herzegovina in 6-10 November 2019.

\section{References}

Abell, S. K., \& Siegel, M. A. (2011). Assessment literacy: What science teachers need to know and be able to do? In D. Corrigan, J. Dillon, R. Gunstone (Eds.). The professional knowledge based of science teaching. Netherlands: Springer. https://doi. org/10.1007/978-90-481-3927-9

Bayat, S., \& Şentürk, Ş. (2015) Physics, Chemistry, Biology teachers' views on alternative assessment and evaluation techniques in secondary school. Amasya Education Journal, 4(1), 118-135.

Black, P., \& Wiliam, D. (1998). Assessment and classroom learning. Assessment in Education: Principles, Policy \& Practice, 5(1), 7-74. http://dx.doi.org/10.1080/0969595980050102

Bogdan, C. R. \& Biklen, S. K. (2007). Qualitative research for education: An introduction to theory and methods (5 $5^{\text {th }}$ Ed.). Pearson.

Box, C., Skoog, G., \& Dabbs, J. M. (2015). A case study of teacher personal practice assessment theories and complexities of implementing formative assessment. American Educational Research Journal, 52(1), 956-983. https://doi. org/10.3102/0002831215587754

Büyüköztürk, Ş., Kiliç-Çakmak, E., Akgün, Ö. E., Karadeniz, Ş. \& Demirel, F. (2008). Scientific research methods (2 ${ }^{\text {nd }}$ Ed.). Pegem.

Chen, B., \& Wei, B. (2015). Examining chemistry teachers' use of course materials: In view of teachers' pedagogical content knowledge. Chemistry Education Research and Practice, 16, 260-272. https://doi.org/10.1039/C4RP00237G

Cooper, B., \& Cowie, B. (2010). Collaborative research for assessment for learning. Teaching and Teacher Education, 26, 979-986. https://doi.org/10.1016/j.tate.2009.10.040

Cowie, B., \& Bell, B. (1999). A model of formative assessment in science education. Assessment in Education: Principles, Policy \& Practice, 6(1), 111-116. https://doi.org/10.1080/09695949993026

Gelbal, S., \& Kelecioğlu, H. (2007). Teachers' proficiency perceptions of about the measurement and evaluation techniques and the problems they confront. Hacettepe University Journal of Education, 33, 135-145.

Izci, K., \& Siegel, M. A. (2019). Investigation of an alternatively certified new high school chemistry teacher's assessment literacy. International Journal of Education in Mathematics, Science and Technology, 7(1), 1-19. https://doi.org/10.18404/ijemst.473605

Looney, A., Cumming, J. Kleij, F. V. D., \& Harris, K. (2017). Reconceptualising the role of teachers as assessors: teacher assessment identity. Assessment in Education: Principles, Policy \& Practice, 25(5), 442-467. http://dx.doi.org/10.1080/096959 4X.2016.1268090

Lyon, E. G. (2013). Learning to assess science in linguistically diverse classrooms: Tracking growth in secondary science preservice teachers' assessment expertise. Science Education, 97(3), 442-467. https://doi.org/10.1002/sce.21059

McMillan, J. H., \& Schumacher, S. (2010). Research in education: Evidence-based inquiry (7 $7^{\text {th }}$ Ed.). Pearson Education.

Meriam, S. B. (1998). Qualitative research and case study applications in education: Revised and expanded form case study research in education. Jossey-Bass Publishers. 
Mertler, C. A., \& Campbell, C. (2005 April). Measuring teachers' knowledge and application of classroom assessment concepts: Development of the "Assessment Literacy Inventory. Paper presented at the Annual Meeting of the American Educational Research Association, Montreal, QC.

Miles, M. B., \& Huberman, A. M. (1994). Qualitative data analysis: An expanded sourcebook (2 ${ }^{\text {nd }}$ Ed.). Sage Publications.

Minister of National Education (MoNE) (2017). Draft Line of Chemistry Curriculum grade 9.10. 11 and 12. Devlet Kitapları Müdürlüğü. Minister of National Education (MoNE) (2018). Chemistry Curriculum grade 9.10. 11 and 12. Devlet Kitapları Müdürlüğü.

Nazlıçiçek, N., \& Akarsu, F. (2008). Physics, Chemistry and Mathematics teachers' approaches to assessment tools and their assessment practices. Education and Science, 33(149), 18-29.

Özgeç, M., \& Çakır, M. (2015). Exploring primary school teachers' competencies of alternative assessment and evaluation. Elementary Education Online, 14(3), 914-933. http://dx.doi.org/10.17051/io.2015.22900

Popham, W. J. (2006). All about accountability / Assessment for learning: An endangered species? Educational Lidership, 63(5), $82-83$.

Sağlam-Arslan, A., Devecioğlu-Kaymakçı, Y., \& Arslan, S (2009). Problems concerning alternative evaluation methods: The case of science and technology teachers. Ondokuz Mayıs Üniversitesi Eğitim Fakültesi Dergisi, 28, 1-12.

Sözbilir, M., Kutu, H., \& Yaşar, M. D. (2012). Science education research in Turkey: A content analysis of selected features of papers published. In D. Jorde \& J. Dillon (Eds.) Science Education Research and Practice in Europe: Retrospective and Prospective (pp.341-374). Sense Publishers.

Sözbilir, S., Akıllı, M., Yaşar, M. D., \& Kutu, H. (2016). Development of chemistry education research (CER) in Turkey: A comparison of CER papers with international research. In M.H.Chiu (Ed.), Science education research and practice in Asia: Challenges and opportunities (pp.289-317). Springer. https://doi.org/10.1007/978-981-10-0847-4_16

Şenel, S., Pekdağ, B., \& Günaydın, S. (2018). Chemistry teachers' problems and insufficiencies in educational measurement and evaluation. Necatibey Faculty of Education Electronic Journal of Science and Mathematics Education, 12(1), 419-441. https:// doi.org/10.17522/balikesirnef.437824

Şenel-Çoruhlu, T., Er-Nas, S., \& Çepni, S. (2009). Problems facing science and technology teachers using alternative assessment technics: Trabzon sample. Yüzüncü Yıl Üniversitesi, Eğitim Fakültesi Dergisi, 1 (1), 122-141.

Yaşar, M. D. (2017). Prospective science teachers' perception related to formative assessment approaches in Turkey. Journal of Education and Training Studies, 5(4), 29-43. https://doi.org/10.11114/jets.v5i4.2190

Yıldırım, A., \& Şimşek, H. (2008). Qualitative research methods in social sciences ( $6^{\text {th }}$ Ed.). Seçkin.

Yılmaz-Tüzün, O. (2008). Pre-service elementary teachers' beliefs about science teaching. Journal of Science Teacher Education, 19(2), 183-204. https://doi.org/10.1007/s10972-007-9084-1

Wylie, E. C., \& Lyon, C. J. (2015). The fidelity of formative assessment implementation: Issues of breadth and quality. Assessment in Education: Principles, Policy \& Practice, 22(1), 140-160. https://doi.org/10.1080/0969594X.2014.990416

$\mathrm{Xu}, \mathrm{Y} .$, \& Brown, G. T. L. (2016). Teacher assessment literacy in practice: A reconceptualization. Teaching and Teacher Education, $58,149-162$.

Received: September 10, 2019

Accepted: February 00, 2020

Cite as: Yaşar, M. D. (2020). Chemistry teachers' assessment literacy in Turkey. Journal of Baltic Science Education, 19(1), 76-90. https://doi.org/10.33225/jbse/20.19.76

Mehmet Diyaddin Yaşar

PhD, Associate Professor, Mathematics and Science Education

Department, Science Education Division, Harran University, 63190,

Şanlıurfa/Turkey.

E-mail: mdiyaddinyasar@harran.edu.tr 